\title{
Design of a continuous quality improvement program to prevent falls among community-dwelling older adults in an integrated healthcare system
}

\author{
David A Ganz*1,2,3, Elizabeth M Yano ${ }^{1,4}$, Debra Saliba1,2,3,5 and \\ Paul G Shekelle ${ }^{1,3}$
}

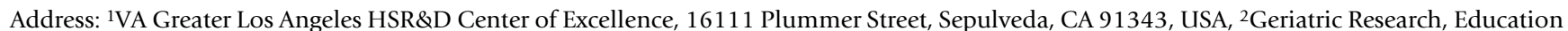
and Clinical Center, Veterans Affairs Greater Los Angeles Healthcare System, 11301 Wilshire Boulevard, Los Angeles, CA 90073, USA, ${ }^{3}$ David Geffen School of Medicine at the University of California at Los Angeles, 10833 Le Conte Avenue, Los Angeles, CA 90095, USA, ${ }^{4}$ School of Public Health, University of California at Los Angeles, 650 Charles E. Young Drive South, Los Angeles, CA 90095, USA and ${ }^{5}$ Borun Center for Gerontological Research, University of California at Los Angeles and Los Angeles Jewish Home, 10945 Le Conte Avenue, Suite 2339, Los Angeles, CA 90095, USA
\end{abstract}

Email: David A Ganz* - David.Ganz@va.gov; Elizabeth M Yano - Elizabeth.Yano@va.gov; Debra Saliba - Debra.Saliba@va.gov; Paul G Shekelle - Paul.Shekelle@va.gov

* Corresponding author

Published: 16 November 2009

BMC Health Services Research 2009, 9:206 doi:10.1 186/1472-6963-9-206

This article is available from: http://www.biomedcentral.com/1472-6963/9/206

(C) 2009 Ganz et al; licensee BioMed Central Ltd.

This is an Open Access article distributed under the terms of the Creative Commons Attribution License (http://creativecommons.org/licenses/by/2.0), which permits unrestricted use, distribution, and reproduction in any medium, provided the original work is properly cited.

\begin{abstract}
Background: Implementing quality improvement programs that require behavior change on the part of health care professionals and patients has proven difficult in routine care. Significant randomized trial evidence supports creating fall prevention programs for community-dwelling older adults, but adoption in routine care has been limited. Nationally-collected data indicated that our local facility could improve its performance on fall prevention in community-dwelling older people. We sought to develop a sustainable local fall prevention program, using theory to guide program development.
\end{abstract}

Methods: We planned program development to include important stakeholders within our organization. The theory-derived plan consisted of I) an initial leadership meeting to agree on whether creating a fall prevention program was a priority for the organization, 2) focus groups with patients and health care professionals to develop ideas for the program, 3) monthly workgroup meetings with representatives from key departments to develop a blueprint for the program, 4) a second leadership meeting to confirm that the blueprint developed by the workgroup was satisfactory, and also to solicit feedback on ideas for program refinement.

Results: The leadership and workgroup meetings occurred as planned and led to the development of a functional program. The focus groups did not occur as planned, mainly due to the complexity of obtaining research approval for focus groups. The fall prevention program uses an existing telephonic nurse advice line to I) place outgoing calls to patients at high fall risk, 2) assess these patients' risk factors for falls, and 3) triage these patients to the appropriate services. The workgroup continues to meet monthly to monitor the progress of the program and improve it.

Conclusion: A theory-driven program development process has resulted in the successful initial implementation of a fall prevention program. 


\section{Background}

Falls are common in older people, occurring annually in one quarter to one third of community-dwelling adults age $\geq 65$ [1]. These falls pose a serious problem, both because of associated injuries (e.g., hip fractures) [2] and because of the falls' psychological impact on patients [3]. Older adults may restrict their activities in response to a fall, leading to a loss of independence and ability to carry out life's routine tasks. Research evidence has shown that both gentle exercise to improve strength and balance and multifactorial fall prevention programs can reduce future falls in community-dwelling older adults who participate in randomized, controlled trials $[4,5]$. These fall prevention programs often involve a range of providers and interventions to address the various contributing risks that lead to a fall [6]. Risk factors uncovered during an evaluation lead to targeted interventions (such as exercise for lower extremity strength and improved balance, discontinuation of medications that increase fall risk, or installation of grab bars in the bathroom).

Clinical practice guidelines recommend multifactorial fall prevention strategies for patients at high risk of subsequent falls [7]. However, recent attempts to implement fall prevention activities in routine practice have met with mixed results [8-11]. Even in situations where strong evidence supports a program, mixed results in implementation may relate to the context in which the program was implemented, or the process used to facilitate program implementation [12]. This article reports on the process we used to develop a fall prevention program for community-dwelling older adults served by our local healthcare system, as well as key contextual features of our system. We also lay out the theoretical support for our program development process. We hope to stimulate discussion regarding the merits of different strategies for implementing evidence into routine care, particularly for complex programs that require a confluence of support from diverse stakeholders.

\section{Methods \\ Ethics Approvals}

This study conforms to the ethical principles in the Helsinki Declaration, and received ethics approval from the VA Greater Los Angeles Healthcare System (PCC 2008010128) and University of California at Los Angeles (G08-06-103-01) Institutional Review Boards. Because of the minimal risk nature of this project, the Institutional Review Boards waived the requirement for written informed consent.

\section{Setting}

The Veterans Affairs Greater Los Angeles Healthcare System (VAGLAHS) is an integrated healthcare system serving veterans living in a catchment area that spans the metropolitan Los Angeles area. The system includes one acute care hospital with clinics, two community living centers, two ambulatory care centers offering primary care and some specialty services, and ten community-based outpatient clinics that offer mostly primary care. VAGLAHS serves a disproportionately older population; nearly one-quarter of all patients are age $\geq 75$, and therefore, a large group of VAGLAHS patients are at risk for falls. In absolute terms, VAGLAHS served a total of 19,257 unique patients age $\geq 75$ in its primary care clinics over a two-year period (September 1, 2005 to August 31, 2007) (unpublished data).

VAGLAHS is a globally budgeted, capitated healthcare system. Virtually all healthcare providers are salaried, and all clinicians use a shared electronic health record. VAGLAHS is one of five healthcare systems in the Desert Pacific Healthcare Network, which serves Southern California and Southern Nevada. This network, which finances VAGLAHS' operations, is one of 21 networks in the United States Veterans Health Administration (VA).

The national VA Office of Quality and Performance runs the External Peer Review Program (EPRP) to monitor the quality of care provided by VA facilities. In the case of fall prevention, quality indicators previously developed by the RAND Assessing Care of Vulnerable Elders (ACOVE) project (for ACOVE methods, see sources [13] and [14]) were adopted by the EPRP on a pilot basis for VA outpatients age $\geq 75$. These quality indicators are called VA "supporting indicators" because they are not being used to judge facility or network performance, but rather to provide initial information to the Office of Quality and Performance regarding quality of care. Quality indicators are monitored by reviewing a random sample of medical records at VA facilities.

There are two supporting indicators for fall prevention: the first indicator states that outpatients age $\geq 75$ should be asked about falls in the preceding year. To determine adherence to this indicator, medical record reviewers are asked: "Within the past twelve months, was the patient asked about the presence/absence of any falls within the preceding 12 months?" The second indicator states that a basic fall evaluation should be performed on outpatients age $\geq 75$ with two falls, or at least one fall with injury requiring treatment, in the past year. To determine whether a basic fall evaluation was performed, reviewers search the medical record for documentation of five elements: 1) circumstances of the fall, 2) medications the patient is taking, 3) relevant chronic conditions, 4) diagnostic plans/therapeutic recommendations, and 5) documentation of action taken as appropriate. Although these quality indicators are monitored at the national level, they are not in the first tier of performance measures for which 
VA managers are held accountable. However, facility-level quality of care scores for these indicators are available internally to VA managers, clinicians, and researchers on the VA Intranet. In addition, through a data use agreement, researchers may obtain more detailed data from the Office of Quality and Performance.

We obtained data for the first quality indicator for falls asking outpatients age $\geq 75$ about falls in the past year -for Fiscal Year 2007 (October 1, 2006 to September 30, 2007), the first year during which these data were collected. There was marked variation between VA facilities (such as VAGLAHS) in how often outpatients age $\geq 75$ were asked about falls in the past year (Figure 1). On average, $33 \%$ of patients nationwide were asked about falls (facility $\mathrm{N}=139$, patient $\mathrm{N}=27899$ ), similar to a $25 \%$ rate seen among vulnerable older adults in two managed care organizations outside the VA system [15]. Although this quality indicator was not designed to compare facilities with one another, additional analyses (not shown) revealed that our local facility's performance needed to improve, regardless of whether the national average, or a higher benchmark, was set as the target.

The second quality indicator -- performing a basic fall evaluation on outpatients age $\geq 75$ with two falls (or one fall with injury requiring treatment) in the past year - was satisfied in $36 \%$ of eligible cases nationally (Patient $\mathrm{N}=$ 899). The sample size for this indicator was too small to compare our local facility performance to the national average. However, this indicator is coupled to the previous one - asking more adults age $\geq 75$ about falls in the

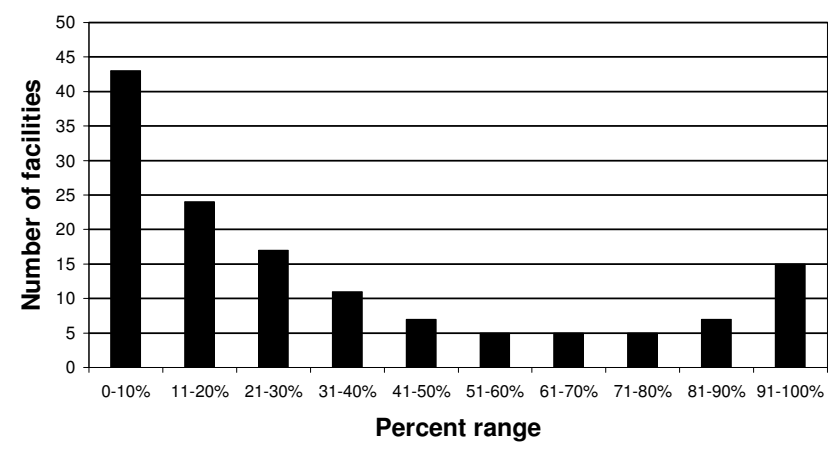

Figure I

Adherence of I 39 VA facilities to asking outpatients age $\geq 75$ about falls in the past year. Data are derived from VA External Peer Review Program data from Fiscal Year 2007 (October I, 2006 to September 30, 2007) based on a review of a random sample of medical records at each facility. The $Y$-axis indicates the number of facilities in a particular adherence range. The $X$-axis groups facilities by the percent of patients who were asked about falls. preceding year (indicator \#1) will result in the detection of more high-risk cases requiring a basic evaluation (indicator \#2). Thus, improving the quality of care for falls at our facility requires both better detection of patients with a significant fall history and better ways to address fall risk factors among high-risk patients.

Table 1 summarizes the various contextual factors that might affect successful implementation of a fall prevention program at VAGLAHS. The categories in Table 1 come from a systematic review of factors critical to successful implementation of prevention programs, based on data from actual attempts at implementation [16].

\section{Program development}

In order to improve the quality of care for fall prevention provided to outpatient veterans at VAGLAHS, we envisioned a program development process that would harmonize stakeholder interests towards the goal of producing a pilot fall prevention program that could be implemented, sustained, and further improved. In keeping with previous work on translating research into practice [17], we drew on multiple theories, as well as previous experience, to plan program development and implementation. We built on organizational theory [18], previous efforts to set strategic priorities within the VA [19], diffusion of innovations theory [20], and (for implementation) principles of continuous quality improvement [21]. We discuss each of these elements in the paragraphs that follow.

Organizational theory helped us conceptualize the initial phase of program development. We drew upon a typology of organizational responses described in Oliver's "Strategic Responses to Institutional Processes" [18]. Oliver theorized that organizations respond in five typical ways to pressures to change business as usual: 1) acquiescence, 2) compromise, 3) avoidance, 4) manipulation and 5) defiance. She then laid out ten hypotheses as to what influences an organization's response to external pressure. Here, we focus on six of these hypotheses. Organizations are more likely to comply with external pressures if these pressures are viewed as 1) socially legitimate, 2) economically efficient, 3) not in conflict with other external demands on the organization, 4) consistent with institutional norms, 5) not constraining the organization's ability to act, and 6) voluntarily diffusing into the organization [18].

Oliver's framework and previous efforts at priority-setting in the VA system [19] suggested that our first development step should be to sound out leaders within our organization to verify that they valued implementing a fall screening and prevention program. Since organizational leaders represent organizations, their support is necessary (albeit 
Table I: Factors potentially affecting implementation of the fall prevention program in the VA Greater Los Angeles Healthcare System (VAGLAHS) (factors adapted from Durlak and DuPre [16]).

Key factors Status of these factors in fall prevention program

I. Community level factors

\begin{tabular}{cl}
\hline A. Prevention theory and research & $\begin{array}{l}\text { There is a well developed research literature on fall prevention. Theory, however, is } \\
\text { less well developed. }\end{array}$ \\
\hline B. Politics & $\begin{array}{l}\text { The political environment has some awareness of falls [29], although in the United } \\
\text { States this awareness does not rise to the level of other medical concerns such as } \\
\text { cancer and heart disease. }\end{array}$ \\
\hline C. Funding & $\begin{array}{l}\text { There is some funding available for fall prevention activities from United States } \\
\text { government organizations such as the Centers for Disease Control and Prevention as } \\
\text { well as philanthropic organizations (e.g., the Archstone Foundation). However, } \\
\text { funding for these activities does not parallel the availability of funds for other } \\
\text { conditions. }\end{array}$ \\
\hline D. Policy & $\begin{array}{l}\text { Current policies by governmental organizations provide a small but clear level of } \\
\text { support for fall prevention activities [29]. }\end{array}$
\end{tabular}

II. Provider characteristics

A. Perceived need for innovation

B. Perceived benefits of innovation

C. Self-efficacy

D. Skill proficiency

III. Characteristics of the innovation
A. Compatibility

B. Adaptability

IV. Factors relevant to the prevention delivery system: organizational capacity

A. General organizational factors
I. Positive work climate

2. Organizational norms regarding change

3. Integration of new programming
Informal interviews with providers (physicians, nurses) in the ambulatory care setting as well as facility leadership suggest the perceived need for innovation at VAGLAHS is moderate to high.

Different individuals perceive different benefits from an enhanced fall prevention program. Some perceive the potential to save the facility money in reduced costs from inpatient hospital stays due to injuries. Others perceive the possibility of an improvement in quality of care due to better access to fall prevention services for patients. Yet others note that efficiency might be improved by streamlining the array of fall prevention services already in existence.

Providers' self-efficacy in preventing falls is unknown. Investigators at VAGLAHS are funded to develop a survey of primary care providers that will assess this issue.

Providers' skill proficiency in implementing fall prevention activities is unknown. Investigators at VAGLAHS are funded to develop a survey of primary care providers that will assess this issue. 
Table I: Factors potentially affecting implementation of the fall prevention program in the VA Greater Los Angeles Healthcare System (VAGLAHS) (factors adapted from Durlak and DuPre [16]). (Continued)

\begin{tabular}{|c|c|}
\hline B. Specific practices and processes & \\
\hline I. Shared decision-making & $\begin{array}{l}\text { The interest in shared decision-making at VAGLAHS seems to be high. The two } \\
\text { leadership meetings to discuss whether and how the fall prevention program should } \\
\text { be developed and implemented were well-attended, including members of senior } \\
\text { leadership. }\end{array}$ \\
\hline 2. Coordination with other agencies & $\begin{array}{l}\text { Coordination between VAGLAHS and outside agencies that provide fall prevention } \\
\text { activities (e.g., community senior centers) is difficult. The VA's electronic health } \\
\text { record provides a strong incentive to coordinate activities internally. An exception to } \\
\text { this relevant to fall prevention is the use of home care services (including home } \\
\text { physical therapy and home safety evaluations), which can be ordered through the VA } \\
\text { electronic health record but then may be contracted to a private home health agency, } \\
\text { and financed either via a veteran's health insurance benefits or by direct payment } \\
\text { from the VA to an outside agency. }\end{array}$ \\
\hline 3. Communication & $\begin{array}{l}\text { Communication is facilitated by a common internal e-mail system and phone } \\
\text { directory. }\end{array}$ \\
\hline 4. Formulation of tasks & $\begin{array}{l}\text { Task formulation was enhanced by the Chief of Staff's chartering a workgroup } \\
\text { composed of members from different disciplines relevant to fall prevention } \\
\text { (ambulatory care, geriatrics, physical medicine \& rehabilitation, nursing, performance } \\
\text { improvement, research). }\end{array}$ \\
\hline
\end{tabular}

C. Specific staffing considerations

I. Leadership

2. Program champion
The Chief of Staff of VAGLAHS is a geriatrician and therefore has a heightened appreciation of the need for improved quality of care with respect to fall prevention. $\mathrm{He}$ is supportive of the intervention.

The first author is acting as program champion. This champion status is protected for 5 years through salary support from a VA Career Development Award whose specific aims include the development and implementation of a fall prevention program at VAGLAHS. The first author's career development is supported by two program at VAGLAHS. The first author's career development is suppo
mentors (PGS and DS) and an advisory committee (including EMY).

3. Managerial/supervisory/administrative support

Administrative support for the development of the fall prevention program is limited.

V. Factors related to the prevention support system

A. Training

B. Technical assistance
The first author has provided continuing medical education about fall prevention to VAGLAHS providers through lectures at various sites within the system. VAGLAHS has a variety of more general training programs that could be harnessed to increase awareness of the importance of fall prevention.

Currently, the first author provides technical assistance to clinicians involved with the Currently, the first author provides technical assistance to clinicians involved with the
project on an ad hoc basis. Developing more formal technical assistance for providers will become necessary if the program advances beyond its pilot phase. not sufficient) for successful implementation. Second, whatever we proposed to leaders could not violate Oliver's hypotheses regarding which organizational changes are most likely to be acceptable. In our local context, this meant that we could not ask for new staff (which would violate the notion of economic efficiency), and we would need to spread the program's workload across all involved departments to avoid adversely affecting any one department.

The first step of the program development plan involved holding an initial meeting with VAGLAHS leadership, including the Chief of Staff (i.e., medical director). The goal of this first meeting was to ascertain whether managers within VAGLAHS agreed on a) the importance of fall prevention b) the strategies for preventing falls among community-dwelling veterans, and c) a broad outline of how these strategies might be accomplished. The first author's role in this process was to present evidence from the research literature about strategies for fall prevention, as well as the data on VA national and local performance in fall prevention, discussed earlier.

In our original program development plan, the next step was to hold focus groups of patients and employees who would likely be involved with the program. We did not hold these focus groups for two reasons. First, we did not hold focus groups of employees because we received feedback that employees might not be comfortable speaking candidly in the presence of other employees in the same 
organization. In addition, since the lead author had already conducted one-on-one interviews with multiple different employees prior to program development, reinterviewing employees seemed likely to have less incremental benefit than we originally had envisioned. Regarding patient focus groups, our status as a research study meant the need to obtain Institutional Review Board approval of focus group content and would have lengthened the program development process by three to six months. Since the program development process moved faster than anticipated, we decided not to pursue patient focus groups. Instead, we decided to use patient and stakeholder interviews to evaluate the first cycle of program development (discussed later).

The third step of the program development process was to constitute a workgroup of representatives from different disciplines involved in fall prevention to create a concrete plan. We aimed to identify workgroup members who represented the interests of various stakeholders, could provide insight regarding institutional norms and resources, and comprised a mix of content experts in fall prevention and clinicians and practitioners of quality improvement.

The fourth step was to hold a second leadership meeting to present the workgroup's suggested plan and receive feedback. Compared to the first meeting, this second meeting would be more focused on discussing specific options for the content of the fall prevention program, based on the findings of the workgroup.

Oliver's framework helped in choosing a program development and implementation process but did not directly address characteristics of a program itself that would make it more likely to be implemented successfully, issues that would matter to the workgroup. We used a systematic review of diffusion of innovations by Greenhalgh [20] to identify the following program attributes as being key for successful adoption:

- Simplicity--simpler innovations are more likely to be adopted than complex innovations

- Trialability--innovations that can be tested and experimented with are more likely to be adopted

- Observability--If adopters can see the benefits of an innovation, the innovation will be more easily adopted

- Reinvention--innovations that can be modified or refined to suit adopters' needs are more likely to be adopted
- Risk - innovations that are less risky are more likely to be adopted

In conformance with the principle of simplicity, we decided that any research on the program should not interfere with program delivery. In keeping with the principles of trialability, reinvention, observability, and risk minimization, we envisioned program implementation as being consistent with continuous quality improvement methodology, specifically including several concepts described by Locock:

- "Continuous incremental improvement of current processes--repeated testing and evaluation of small scale changes.

- Responsibility for quality in the hands of frontline staff.

- Collective team responsibility.

- Detailed meticulous measurement." [21]

This continuous quality improvement process would take place on an ongoing basis as the program was implemented.

\section{Results}

The first leadership meeting (in February 2008) began with a ten-minute presentation of national data (Figure 1) and facility-level data. Seventeen people attended. At the meeting, multiple participants indicated that any new program should not "overwhelm the system" given a variety of competing clinical and quality improvement demands. The meeting closed with the Chief of Staff chartering a collaborative workgroup to develop a pilot outpatient fall prevention program.

The workgroup first met in April 2008, and consisted of at least one representative nominated from each of five departments: primary care, nursing, geriatrics, physical medicine \& rehabilitation, and performance improvement. The first author, a researcher and clinician, served as a content expert regarding the evidence base for fall prevention. The workgroup met monthly and was attended by five to seven people at any given meeting.

The first workgroup session involved brainstorming. Subsequently, a confidential ballot was sent by e-mail to workgroup participants to rank ideas from the brainstorming session, as well as some additional ideas that had come up in the interim (see additional file 1). The second workgroup meeting involved discussing the feasibility of the eight candidate ideas that received two or more votes on the ballot. Convergence on a lead idea for the fall 


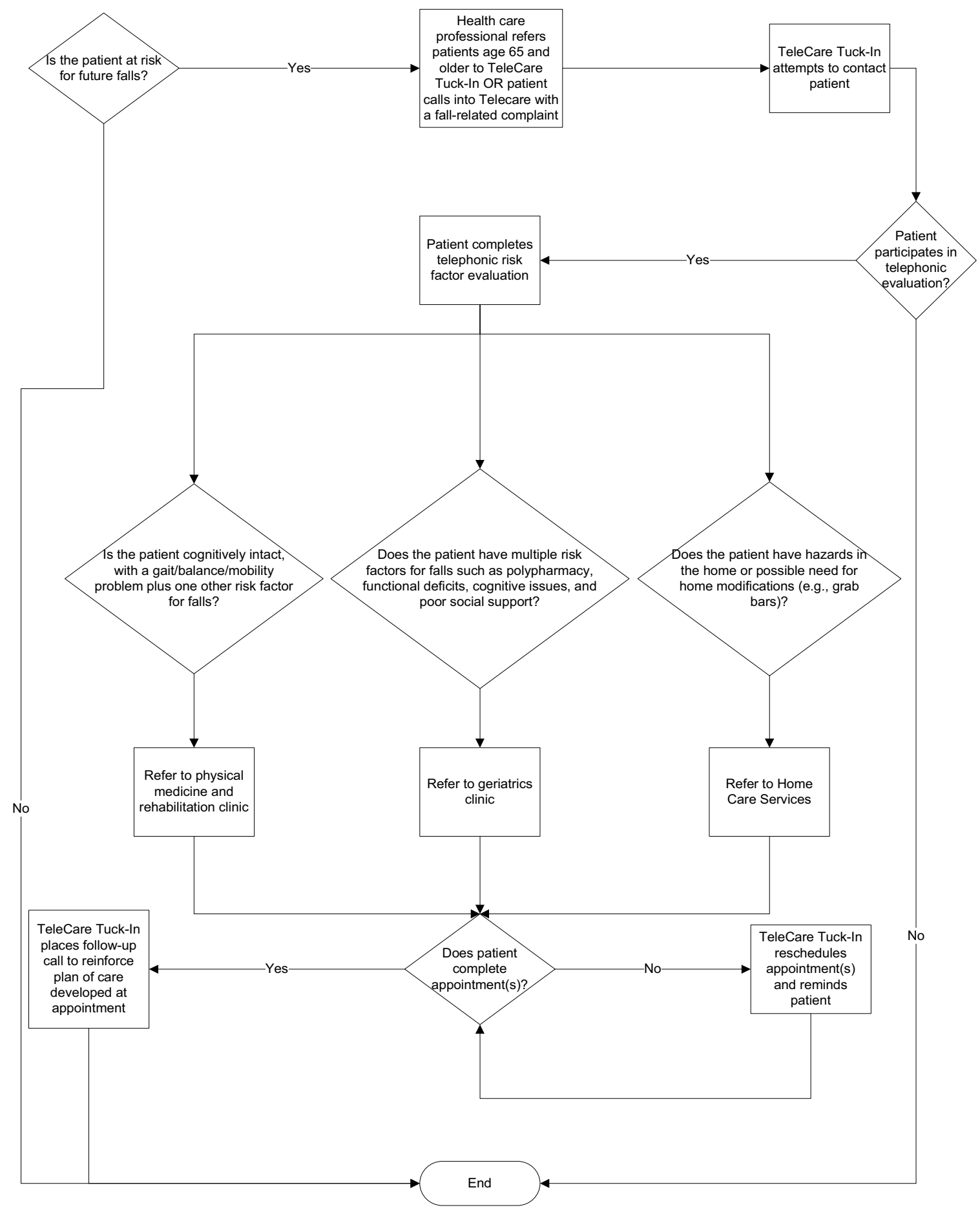

\section{Figure 2}

Preliminary flow diagram of care model. Relevant terms: Telecare: Telephonic advice line accepting incoming calls from patients with medical concerns. Telecare Tuck-In: Service that places outgoing calls to patients (typically at the request of a health care professional, but modified in this instance to follow up on relevant incoming calls by patients). Home care services: Arranges services provided in a patient's home, including any or all of the following services: home physical therapy, home occupational therapy, home safety evaluation, visiting nurse. 
prevention program occurred during the June 2008 workgroup meeting, a joint convening of the workgroup and representatives from Telecare, a telephonic nurse advice line that also offers outgoing calls to patients at a provider's request. Subsequent workgroup meetings led to the care model in Figure 2. The fall prevention program provides a central role for the Telecare Tuck-In Program (described below).

The second leadership meeting, held in October of 2008, involved vetting the care model and soliciting additional ideas; twenty-three people attended. The Telecare program screened its first patient in October of 2008 and continues to operate at this time.

\section{Description of the fall prevention program}

The VA Desert Pacific Healthcare Network uses Telecare to field incoming symptom-related calls from patients. Telecare is staffed by nineteen registered nurses and eight clerks, and handles 12,000 to 13,000 calls per month from throughout the Network. Telecare Tuck-In is a component of Telecare; Tuck-In serves VAGLAHS only. In contrast to Telecare's main function of triaging incoming calls, the Tuck-In program places outgoing calls to patients at a healthcare professional's request. These calls might be to check on the patient's well-being or assess a patient's adherence to medications. Providers may only refer non-urgent cases to the Tuck-In program; if a patient is found to require urgent attention, the Tuck-In nurse triages the patient to an Emergency Department or urgent care clinic.

For the fall prevention program, health care professionals from anywhere in VAGLAHS can place a referral to Telecare Tuck-In program to evaluate a patient's risk factors for falls. The Telecare Tuck-In registered nurse then calls the patient and reads him/her (or his/her caregiver) a standard set of scripted questions to assess risk factors for falls, such as whether the individual has impaired vision, gait or balance problems, or need for home modifications (see Additional File 2). The nurse, using a pre-determined algorithm based on the care model in Figure 2, then requests an appointment for the patient for the physical medicine \& rehabilitation falls clinic, geriatrics clinic, and/or home care services. The script and algorithm were developed with the idea of conducting a simplified multifactorial assessment for fall risk factors [6] and tailoring interventions to the patient's needs. Due a need for brevity and the telephonic basis of the assessment, the workgroup decided that not all critical risk factors could be fully assessed.

One month after the initial contact, the Telecare Tuck-In nurse then places a second phone call to the patient to assess the patient's adherence to appointments. Telecare's medical director agreed to support the Telecare Tuck-In nurse in cases where medical authorization is needed for appointments. However, to maintain continuity of care, primary care providers are to be electronically alerted to any notes or referrals completed by the nurse. For the pilot phase of the program, Telecare has also been screening incoming calls from patients who might have a fallrelated concern and routing them to the Telecare Tuck-In nurse for further evaluation.

The Telecare fall prevention program's main advantage is its ability to coordinate existing resources for fall prevention at VAGLAHS. Because Telecare conducts business by phone, it can accept referrals from anywhere in VAGLAHS, even geographically remote areas. Another potential advantage of the Telecare fall prevention program is the opportunity to unburden primary care providers of additional responsibilities by helping assess patients' needs and arranging the appropriate services.

Areas currently being explored include determining the best combination of referral sources to the program (e.g., Telecare itself, primary care, patient self-referral, urgent care, or the Emergency Department) as well as which individuals will most commonly make referrals (e.g., social workers, nurses, physicians, or patients self-referring). Another area that requires additional exploration is the best way to routinely track completion of recommended activities (e.g., home safety evaluation) for patients who participate in the program. In addition, a new phase of the program, encouraged by workgroup participants, is starting (see additional file 3 ).

\section{Program evaluation}

The fall prevention workgroup, which has continued beyond its initial 6-month charter, serves as a forum for ongoing program evaluation. Participation is now voluntary, and the group meets via conference call to facilitate participation. Workgroup meetings are used to troubleshoot emerging issues (e.g., timely completion of a fall prevention referral to Telecare), as well as to discuss new ideas. Five to nine participants typically join each call.

In addition to the ongoing evaluation that occurs as part of the Telecare fall prevention program itself, a research evaluation of the Telecare fall prevention program is planned. This research evaluation will involve reviewing a log to see how many individuals were screened for the program, as well as performing interviews with patients who participated in the program. The evaluation will also interview stakeholders who help run the program, refer patients to it, or are referred patients from the program. We will assess interviewees' satisfaction with the program as well as solicit ideas for improvement. The evaluation will also review patients' medical records to assess how 
well the pilot program is being implemented, as well as the overall quality of care patients received for fall prevention. Medical record review will use quality indicators for care of vulnerable older adults with falls and mobility disorders [22], for which benchmark data from non-VA sites are available [23]. Given the incremental approach we have taken, we do not expect the evaluation of the first iteration of the Telecare fall prevention program to demonstrate uniformly positive findings, but do think it will yield more concrete areas for improvement efforts.

\section{Discussion}

Multifactorial fall programs are complex to implement in the outpatient setting because they require cooperation between multiple healthcare professionals as well as changes in patients' behavior. A recent organizational survey of managers in the United Kingdom attests to the difficulties in implementing multifactorial fall prevention programs in routine care, even when there is a national mandate to do so [24]. With respect to our own program, we are concerned by recent data suggesting that programs that directly mitigate patients' risk factors for falls may be more successful than those that depend on patients to complete referrals to other providers [25]. Indeed, a recent process evaluation of a fall prevention program with negative results suggests that patients' failure to follow up with their general practitioner was an important reason that the study was not implemented as planned [26]. As a consequence, a significant part of our program evaluation will focus on whether our patients are completing referrals made for them.

We have some early observations about program development. First, our program development and implementation process has been non-linear. For the first six months, the workgroup's intensity of effort was quite high, and then settled into a maintenance phase after implementation of the program had begun. Second, program development was a hybrid of "bottom-up" and "top-down" approaches [27]. Although the workgroup functioned autonomously once it was chartered, we benefited crucially from leadership support for creation of the workgroup. For example, we explicitly sought and received support from our local facility's Chief of Staff for our efforts. In addition, decisions by VA national leadership to measure and internally report facility-level quality of care for falls provided us with evidence to convince our local facility's leadership that care should be improved.

Third, the program development process unfolded over the good part of a year, and we are still early in the process of implementation. Although slow, this pace is likely to improve sustainability, since participants carry out their program-related duties as part of their usual workload. Fourth, we lack easily obtainable metrics to determine whether care is improving. This contrasts with inpatient fall prevention programs, where data on fall and injury rates are often captured as part of adverse event reporting systems, and can be tracked quarterly to measure response to incremental changes made to improve care. In the outpatient setting, it can be difficult to capture detailed data on falls without turning a quality improvement program into a research study, since most falls in communitydwellers occur outside the four walls of the healthcare system and may not be reported by the patient to a health care provider until months after the fall occurred. Instead, we are relying on continuous quality improvement strategies on a real-time basis to monitor intermediate steps in the process of care, such as completion rates for home safety evaluations that are ordered. In the future, it may be possible to shorten improvement cycles with real-time measures of quality of care for falls using electronic health record data.

Last, we anticipate new questions with regard to diffusion and dissemination of the program should our initial evaluation of the program prove positive. Even though our program development process uses existing staff to implement the program, we still benefit from highly motivated individuals who have willingly taken on new duties to improve the quality of care. Although participants in the workgroup may have participated because of a supervisor's request, the degree of participants' involvement has been determined by their own level of interest in and commitment to fall prevention. Extending quality improvement activities beyond the immediate environments that can be affected by workgroup participants to other areas of our system could prove challenging. When we have our initial evaluation results, we plan to reapproach our facility's clinical leadership and discuss possible next steps for diffusion and dissemination.

\section{Conclusion}

Our program development process is proving sustainable thus far. Since its inception, the multidisciplinary workgroup has continued to meet monthly. The goal of the program development process was to create an initial effort that was sustainable enough to demonstrate a small success to our organization, generating goodwill and the opportunity to improve the program over time, in keeping with continuous quality improvement principles [28]. By these criteria, we believe the initial phase of the development process has been a success.

\section{Competing interests}

The authors declare that they have no competing interests.

\section{Authors' contributions}

DAG, EMY, DS, and PGS developed the conceptual framework for the program development and implementation 
process. EMY and DG analyzed the External Peer Review Program data. DAG drafted the manuscript. EMY, DS, and PGS provided comments for critical revision of the manuscript. All authors read and approved the final manuscript.

\section{Additional material}

\section{Additional file 1}

Instructions and ballot sent to workgroup participants.

Click here for file

[http://www.biomedcentral.com/content/supplementary/1472-

6963-9-206-S1.DOC]

\section{Additional file 2}

Patient script used by Telecare Tuck-In nurse.

Click here for file

[http://www.biomedcentral.com/content/supplementary/1472-

6963-9-206-S2.DOC]

\section{Additional file 3}

Description of new fall prevention program elements, including nurse clinical reminder to assess fall risk in patients age $\geq 75$ and electronic health record menu options for fall prevention.

Click here for file

[http://www.biomedcentral.com/content/supplementary/14726963-9-206-S3.DOC]

\section{Acknowledgements}

This work was funded by the U.S. Department of Veterans Affairs, Veterans Health Administration, VA Health Services Research \& Development (HSR\&D) Service through the VA Greater Los Angeles HSR\&D Center of Excellence (Project \# VA CD2 08-012-I). Additionally, David Ganz received support from the UCLA Older Americans Independence Center, $\mathrm{NIH} / \mathrm{NIA}$ Grant P30-AG028748. This research was partially supported by a locally initiated project grant from Greater Los Angeles VA Health Services Research \& Development Center of Excellence (LIP 65-I50). The VA Office of Quality and Performance supports the VA External Peer Review Program and provided data reported in this manuscript. The authors thank Linda Aoyama, Tammy Czarnecki, Lynn McQueen, Brian Mittman, and Lisa Rubenstein for comments on an earlier draft of this manuscript, Mingming Wang for programming assistance, and Barbara Simon for assistance with study design. We also thank all of the employees of VA Greater Los Angeles Healthcare System who have made the fall prevention program possible.

The views expressed in this article are those of the authors and do not necessarily reflect the position or policy of the U.S. Department of Veterans Affairs, the National Institute on Aging or the National Institutes of Health.

\section{References}

I. Ganz DA, Bao Y, Shekelle PG, Rubenstein LZ: Will my patient fall? JAMA 2007, 297( I):77-86.

2. Tinetti ME: Clinical practice. Preventing falls in elderly persons. N Engl J Med 2003, 348(I):42-49.

3. Scheffer AC, Schuurmans MJ, van Dijk N, Hooft T van der, de Rooij SE: Fear of falling: measurement strategy, prevalence, risk factors and consequences among older persons. Age Ageing 2008, 37(I): 19-24.

4. Sherrington C, Whitney JC, Lord SR, Herbert RD, Cumming RG, Close JC: Effective exercise for the prevention of falls: a sys- tematic review and meta-analysis. I Am Geriatr Soc 2008 , 56( I 2):2234-2243.

5. Beswick AD, Rees K, Dieppe P, Ayis S, Gooberman-Hill R, Horwood J, Ebrahim S: Complex interventions to improve physical function and maintain independent living in elderly people: a systematic review and meta-analysis. Lancet 2008 , 37 I (96 | 4):725-735

6. Chang JT, Morton SC, Rubenstein LZ, Mojica WA, Maglione M, Suttorp MJ, Roth EA, Shekelle PG: Interventions for the prevention of falls in older adults: systematic review and meta-analysis of randomised clinical trials. BMJ 2004, 328(744I):680.

7. American Geriatrics Society, British Geriatrics Society, American Academy of Orthopaedic Surgeons Panel on Falls Prevention: Guideline for the prevention of falls in older persons. J Am Geriatr Soc 200I, 49(5):664-672.

8. Whitehead C, Wundke R, Crotty M, Finucane P: Evidence-based clinical practice in falls prevention: a randomised controlled trial of a falls prevention service. Aust Health Rev 2003. 26(3):88-97.

9. Tinetti ME, Baker DI, King M, Gottschalk M, Murphy TE, Acampora D, Carlin BP, Leo-Summers L, Allore HG: Effect of dissemination of evidence in reducing injuries from falls. N Engl J Med 2008 , 359(3):252-26I.

10. Elley CR, Robertson MC, Garrett S, Kerse NM, McKinlay E, Lawton $B$, Moriarty H, Moyes SA, Campbell AJ: Effectiveness of a fallsand-fracture nurse coordinator to reduce falls: a randomized, controlled trial of at-risk older adults. J Am Geriatr Soc 2008, 56(8): I383-| 389.

II. Hendriks MR, Bleijlevens MH, van Haastregt JC, Crebolder HF, Diederiks JP, Evers SM, Mulder WJ, Kempen GI, van Rossum E, Ruijgrok JM, et al.: Lack of effectiveness of a multidisciplinary fall-prevention program in elderly people at risk: a randomized, controlled trial. J Am Geriatr Soc 2008, 56(8): I 390-I 397.

12. Kitson A, Harvey G, McCormack B: Enabling the implementation of evidence based practice: a conceptual framework. Qual Health Care 1998, 7(3): 149-158.

13. Shekelle PG, MacLean CH, Morton SC, Wenger NS: Assessing care of vulnerable elders: methods for developing quality indicators. Ann Intern Med 200I, I 35(8 Pt 2):647-652.

14. Rubenstein LZ, Powers CM, MacLean CH: Quality indicators for the management and prevention of falls and mobility problems in vulnerable elders. Ann Intern Med 200I, I35(8 Pt 2):686-693

15. Rubenstein LZ, Solomon DH, Roth CP, Young RT, Shekelle PG, Chang JT, MacLean CH, Kamberg CJ, Saliba D, Wenger NS: Detection and management of falls and instability in vulnerable elders by community physicians. J Am Geriatr Soc 2004, 52(9): |527-|53|

16. Durlak JA, DuPre EP: Implementation matters: a review of research on the influence of implementation on program outcomes and the factors affecting implementation. Am J Community Psychol 2008, 4 I (3-4):327-350.

17. Feifer C, Ornstein SM, Jenkins RG, Wessell A, Corley ST, Nemeth LS, Roylance L, Nietert PJ, Liszka H: The logic behind a multimethod intervention to improve adherence to clinical practice guidelines in a nationwide network of primary care practices. Eval Health Prof 2006, 29(I):65-88.

18. Oliver C: Strategic responses to institutional processes. Academy of management review I99|, I 6(I): |45-I79.

19. Rubenstein LV, Fink A, Yano EM, Simon B, Chernof B, Robbins AS: Increasing the impact of quality improvement on health: an expert panel method for setting institutional priorities. Jt Comm J Qual Improv 1995, 2 I (8):420-432.

20. Greenhalgh T, Robert G, Macfarlane F, Bate P, Kyriakidou O: Diffusion of innovations in service organizations: systematic review and recommendations. Milbank $Q$ 2004, 82(4):581-629.

21. Locock L: Healthcare redesign: meaning, origins and application. Qual Saf Health Care 2003, I 2(I):53-57.

22. Chang JT, Ganz DA: Quality indicators for falls and mobility problems in vulnerable elders. J Am Geriatr Soc 2007, 55(s2):S327-S334.

23. Wenger NS, Solomon DH, Roth $\mathrm{CP}$, MacLean $\mathrm{CH}$, Saliba D, Kamberg C], Rubenstein LZ, Young RT, Sloss EM, Louie R, et al.: The quality of medical care provided to vulnerable community-dwelling older patients. Ann Intern Med 2003, I39(9):740-747. 
24. Lamb SE, Fisher JD, Gates S, Potter R, Cooke MW, Carter YH: A national survey of services for the prevention and management of falls in the UK. BMC Health Serv Res 2008, 8:233.

25. Gates S, Fisher JD, Cooke MW, Carter YH, Lamb SE: Multifactorial assessment and targeted intervention for preventing falls and injuries among older people in community and emergency care settings: systematic review and meta-analysis. BMJ 2008, 336(7636): I 30-133.

26. Bleijlevens $M H$, Hendriks MR, van Haastregt $J C$, van Rossum E, Kempen GI, Diederiks JP, Crebolder HF, van Eijk JT: Process factors explaining the ineffectiveness of a multidisciplinary fall prevention programme: a process evaluation. BMC Public Health 2008, 8:332.

27. Parker LE, de Pillis E, Altschuler A, Rubenstein LV, Meredith LS: Balancing participation and expertise: a comparison of locally and centrally managed health care quality improvement within primary care practices. Qual Health Res 2007, I 7(9): I268-I279.

28. Berwick DM: A primer on leading the improvement of systems. BMJ 1996, 3 I 2(703 I):619-622.

29. Ganz DA, Alkema GE, Wu S: It takes a village to prevent falls: reconceptualizing fall prevention and management for older adults. Inj Prev 2008, I 4(4):266-27I.

30. Helfrich CD, Li YF, Mohr DC, Meterko M, Sales AE: Assessing an organizational culture instrument based on the Competing Values Framework: exploratory and confirmatory factor analyses. Implement Sci 2007, 2:13.

\section{Pre-publication history}

The pre-publication history for this paper can be accessed here:

http://www.biomedcentral.com/1472-6963/9/206/pre pub

Publish with Bio Med Central and every scientist can read your work free of charge

"BioMed Central will be the most significant development for disseminating the results of biomedical research in our lifetime."

Sir Paul Nurse, Cancer Research UK

Your research papers will be:

- available free of charge to the entire biomedical community

- peer reviewed and published immediately upon acceptance

- cited in PubMed and archived on PubMed Central

- yours - you keep the copyright

Submit your manuscript here:

http://www.biomedcentral.com/info/publishing_adv.asp 